\title{
REMOVAL OF CHROMIUM (VI) BY ACTIVATED CARBON DERIVED FROM MANGIFERA INDICA
}

\author{
Shashikant.R.Mise ${ }^{1}$, Sugunashree.S.M ${ }^{2}$ \\ ${ }^{I}$ Professor, Department of Civil Engineering, ${ }^{2}$ M.Tech Scholar, Department of Environmental Engineering, \\ PDA College of Engineering Gulbarga \\ srmise45@yahoo.com,suguna2504@gmail.com
}

\begin{abstract}
The removal of chromium (VI) from synthetic sample by adsorption on activated carbon prepared from Mangifera Indica (mango) seed shell have been carried out at room temperature $32 \pm 1^{\circ} \mathrm{C}$. The removal of chromium (VI) from synthetic sample by adsorption on chemical activation (Zinc chloride) with Impregnation ratio's (I.R) 0.25, 0.50, 0.75 for optimum time, optimum dosages and variation of $\mathrm{pH}$ was studied. It is observed that as dosage increases the adsorption increased along with the increase in Impregnation ratio. It was also noted that as I.R. increases the surface area of Mangifera Indica shell carbon increased. Hence the maximum removal efficiency is obtained at I.R ratio of 0.75. The optimum contact time, dosage and pH for carbon with I.R-0.75 was $40 m i n$, $150 \mathrm{mg}$ and 1.50 with removal efficiency of $99.00 \%, 99.20 \%$ and $99.60 \%$ respectively.
\end{abstract}

Keywords: Chromium (VI), Contact time, Dosage, Kinetics, pH, Mangifera Indica.

\section{INTRODUCTION}

'Chromium' is a common pollutant introduced into natural waters due to discharge of variety of industrial wastewaters, is highly toxic and presents a serious threat to human health and environment. 'Chromium is considered as one of the top $16^{\text {th }}$ toxic pollutants and because of its carcinogenic and teratogenic characteristics on the public, it has become a serious health concern. According to the world health organization (W.H.O) drinking water guidelines and ISO10500 , the maximum allowable limit for total chromium is $0.05 \mathrm{mg} / \mathrm{L}^{[3]}$

\subsection{Objectives of the Study:}

The present study has been carried out with the following objectives: The preparation of chemically activated carbon by using Zinc chloride as an activating agent, to study the physico-chemical properties of the prepared carbon, and Detection of chromium (VI) removal as a function of contact time, dosage and $\mathrm{pH}$.

\section{MATERIALS AND METHODS}

\subsection{Material}

The material used for preparing carbon was Mangifera Indica (Mango) seed shell. The scientific name of this fruit is Mangifera Indica, from family Anacardiaceae. Activated carbon made from mango seed shell does not impart any colour, taste and odour to water, when it is added to it. So it is a suitable adsorbent for treatment of chromium contaminated water.

\subsubsection{Characteristics of Mangifera Indica (Mango) Shell Carbon:}

Before using the Mangifera Indica (mango) seed shell carbon as an adsorbent, the characteristics such as moisture content, ash content, $\mathrm{pH}$, decolorizing power, surface area, specific gravity and bulk density of the prepared carbon are studied. The results are shown in Table-1

All the methods of analysis are as per "Standard Methods for the Examination of Water and Wastewater", $19^{\text {th }}$ edition ${ }^{[1]}$.

Table-1 Characteristics of Prepared Activated Carbon

\begin{tabular}{|c|c|c|c|c|}
\hline \multirow[t]{2}{*}{$\begin{array}{l}\text { Sl. } \\
\text { No. }\end{array}$} & \multirow[t]{2}{*}{ Characteristics } & \multicolumn{3}{|c|}{$\begin{array}{c}\text { Chemically activated } \\
\qquad \mathbf{Z n C l}_{2}\end{array}$} \\
\hline & & 0.25 & 0.50 & 0.75 \\
\hline 1 & $\begin{array}{c}\text { Moisture content } \\
(\%)\end{array}$ & 18.00 & 20.00 & 20.50 \\
\hline 2 & Ash content $(\%)$ & 20.37 & 23.75 & 24.52 \\
\hline 3 & $\begin{array}{l}\text { Decolorizing } \\
\text { power, }(\mathrm{mg} / \mathrm{g})\end{array}$ & 27.00 & 28.50 & 31.50 \\
\hline 4 & $\begin{array}{l}\text { Surface area, } \\
\left(\mathrm{m}^{2} / \mathrm{g}\right)\end{array}$ & 505.84 & 859.94 & 935.81 \\
\hline
\end{tabular}




\begin{tabular}{|c|c|c|c|c|}
\hline 5 & $\mathrm{pH}$ & 6.6 & 5.5 & 5.1 \\
\hline 6 & Specific gravity & 0.568 & 0.698 & 0.865 \\
\hline 7 & $\begin{array}{c}\text { Bulk Density, } \\
\left(\mathrm{g} / \mathrm{cm}^{3}\right)\end{array}$ & 0.423 & 0.423 & 0.406 \\
\hline
\end{tabular}

\subsection{Methods}

\subsubsection{Preparation of Activated Carbon Using $\mathbf{Z n c l}_{2}$ as}

\section{Activating Agent:}

The known quantity of washed and dried Mangifera Indica (Mango) shell powder of size 300 Micron was mixed with the activating agent $\left(\mathrm{ZnCl}_{2}\right)$, in required quantity, depending upon the impregnation ratio (I.R).

Impregnation ratio (I.R) $=\frac{\text { Weight of the active agent added }}{\text { Weight of carbonizing material }}$

The carbonising material was filled in the small container in three layers, by compacting each layer without any air space to avoid the loss in weight of the powder. The small container is then placed into a big container, such that sand surrounded the small container completely, the lid of the big container was tightly fitted. Pin hole has been made on the lids of the containers for the escape of organic vapours. Then the setup is kept in Muffle furnace and heated at steady rate to attain the temperature of $800^{\circ} \mathrm{C}$. Thirty minutes after attaining the $800^{\circ} \mathrm{C}$ temperature the furnace was allowed to cool for about 10 hours and then the container is taken out. Activated carbon thus prepared was washed with $0.1 \mathrm{~N} \mathrm{HCl}$ to remove the activating agent, followed by hot distilled water for about 8 times to remove the excess $\mathrm{HCl}$ present in the activated carbon. The activated carbon was dried at $105 \pm 5^{\circ} \mathrm{C}$ then packed in polythene bags and kept in desiccators. ${ }^{[2]}$

\subsubsection{Batch Sorption Experiment}

In batch sorption, a pre-determined powder of adsorbent is mixed with the sample, stirred for a given contact time and subsequently separated by filtration. Powder adsorbent is more suitable for the batch type contact process.

\subsubsection{Selection of Optimum Contact Time:}

The adsorption is strongly influenced by the contact time. To study the effect of contact time, $100 \mathrm{ml}$ of $0.5 \mathrm{mg} / \mathrm{L}$ hexavalent chromium solution of $\mathrm{pH} 2.0 \pm 0.02$, was mixed with $0.1 \mathrm{~g}$ of activated carbon, stirred at different contact times varying from (5mins, $10 \mathrm{mins}, 15 \mathrm{mins}$ up to $60 \mathrm{mins})$. Then filtrate was analyzed for residual chromium (VI) concentration using spectrophotometer.

\subsubsection{Determination of Optimum Dosage of}

\section{Adsorbent:}

To determine the optimum dosage of activated carbon, adsorbent is added to the conical flask in different dosage varying from $(25 \mathrm{mg}, 50 \mathrm{mg}, 75 \mathrm{mg}$ up to $300 \mathrm{mg}$ ), containing $100 \mathrm{ml}$ of $0.5 \mathrm{mg} / \mathrm{L}$ concentration of chromium (VI) solution and $\mathrm{pH}$ is adjusted to $2.0 \pm 0.02$. The solution in the conical flask is subjected to stirring for pre-determined optimum contact time, filtered and analyzed for residual chromium concentration.

The dosage which gives minimum residual concentration is chosen as optimum dosage.

\subsubsection{Selection of Optimum $\mathrm{pH}$ on Hexavalent}

\section{Chromium:}

The extent of adsorption is strongly influenced by the $\mathrm{pH}$ at which adsorption is carried out. The effect of $\mathrm{pH}$ on hexavalent chromium adsorption was studied by performing equilibrium adsorption tests at different initial $\mathrm{pH}$ values. i.e. from 1.25 to 3.0 at an interval of 0.25 . The $\mathrm{pH}$ of solution was adjusted by using $0.1 \mathrm{~N} \mathrm{H}_{2} \mathrm{SO}_{4}$ or $0.1 \mathrm{~N} \mathrm{NaOH}$. The maximum concentration of chromium (VI) removal forms optimum $\mathrm{pH}$.

\section{RESULTS AND DISCUSSIONS}

The efficiency of removal of hexavalent chromium is studied in terms of: Effect of contact time, Effect of dosage and Effect of $\mathrm{pH}$.

\subsection{Effect of Contact Time:}

Contact time has greater influence in the adsorption process. The effect of contact time on removal of chromium (VI) from synthetic sample at $\mathrm{pH} 2 \pm 0.02$ using chemically activated carbon with I.R. $0.25,0.50$ and 0.75 are shown in figure 1 . As I.R. increases optimum time decreases due to the increase in surface area. Optimum contact time for all prepared carbons is listed in table-2.

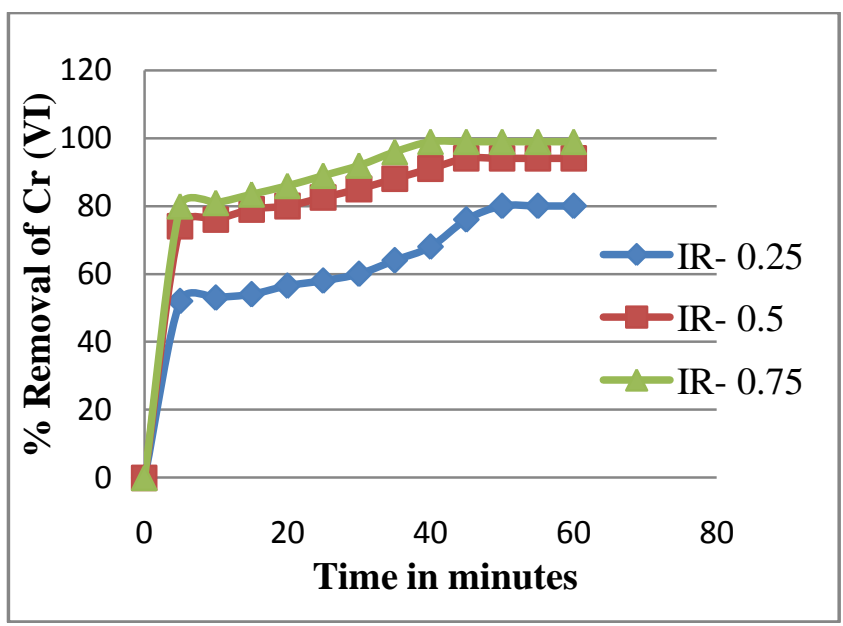


Fig.1. Effect of Contact Time on Cr (VI) Removal by $\mathrm{ZnCl}_{2}$ activated carbon

\subsection{Effect of Adsorbent Dosage:}

Effect of adsorbent dosage is studied and graph of percentage of residual chromium removal versus dosage is plotted as shown in figure 2. From the graph it is observed that, as the dosage of carbon increases, amount of residual chromium (VI) decreases sharply and attains equilibrium. The dosage at which maximum removal is attained, is taken as optimum dosage. After this not much change is observed even after increase in the amount of carbon dosage. The optimum dosage for all prepared carbon are listed in table-2

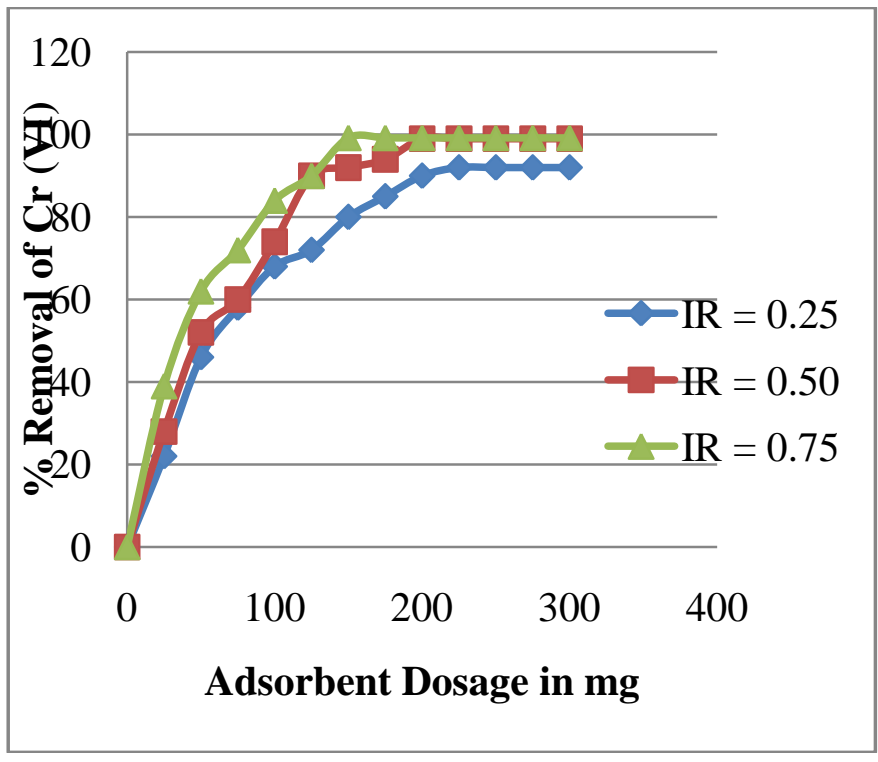

Fig.2.Effect of Adsorbent Dosage on Cr (VI) Removal by $\mathrm{ZnCl}_{2}$ activated carbon

\subsection{Effect of pH on Hexavalent Chromium Removal:}

The $\mathrm{pH}$ of solution has influence on the extent of adsorption removal efficiencies of chromium (VI) by prepared activated carbon at different $\mathrm{pH}$ values are shown in figure 3 . From the figure, it is observed that chromium (VI) is removed more effectively in acidic range. As $\mathrm{pH}$ increases, the removable efficiency decreases appreciably. This is due to the precipitation of carbon surface by nucleation. The optimum $\mathrm{pH}$ for all prepared carbon are listed in table- 2

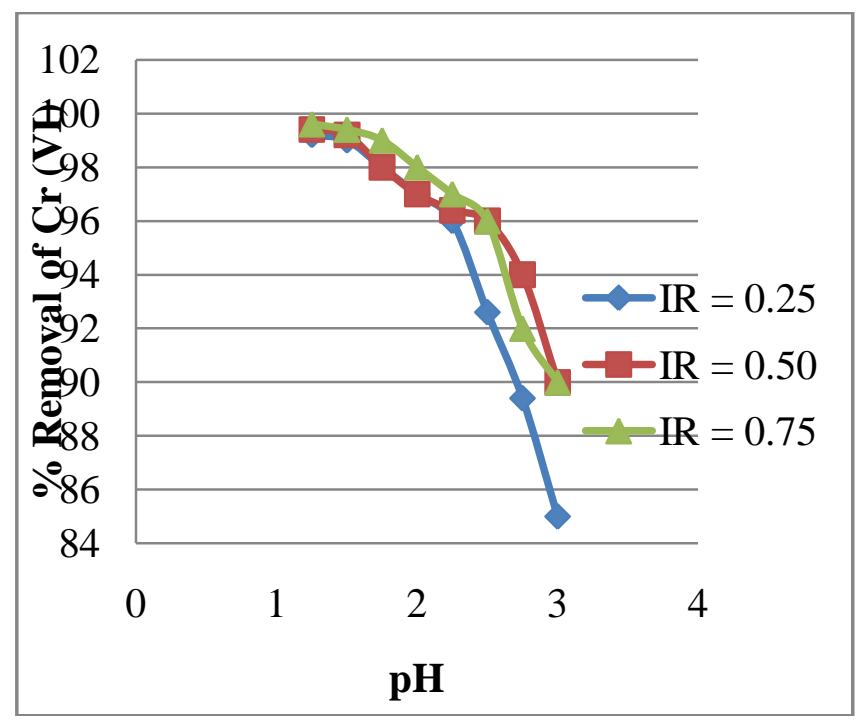

Fig.3.Effect of pH on $\mathrm{Cr}$ (VI) Removal by $\mathrm{ZnCl}_{2}$ Activated Carbon

Table2. Optimum Time, Optimum Dosage and Optimum pH for Prepared Carbons

Initial concentration $=0.5 \mathrm{mg} / \mathrm{L} \quad \mathrm{pH}=2 \pm 0.02$

Volume of sample $=100 \mathrm{~mL} \quad$ Temperature $=32 \pm 1^{\circ} \mathrm{C}$

\begin{tabular}{|l|l|l|l|l|}
\hline $\begin{array}{l}\text { Type Of } \\
\text { Carbon }\end{array}$ & I.R & $\begin{array}{l}\text { Optimum } \\
\text { Time } \\
(\mathrm{min})\end{array}$ & $\begin{array}{l}\text { Optimum } \\
\text { Dosage } \\
(\mathrm{mg})\end{array}$ & $\begin{array}{l}\text { Optimum } \\
\mathrm{pH}\end{array}$ \\
\hline \multirow{2}{*}{$\begin{array}{l}\text { Chemically } \\
\text { activated }\end{array}$} & 0.25 & 50 & 225 & 1.5 \\
\cline { 2 - 5 } & 0.50 & 45 & 200 & 1.5 \\
\cline { 2 - 5 }$(\mathrm{ZnCl} 2)$ & 0.75 & 40 & 150 & 1.5 \\
\hline
\end{tabular}

\section{CONCLUSIONS}

Based on the experimental study the following conclusions were drawn: The extent of chromium adsorption increases with increase in time and attain equilibrium. The result of experiment on optimization of dosage of adsorbent reveals that increase in amount of adsorbent added, increases the removal of $\mathrm{Cr}$ (VI) from the solution and almost becomes constant after saturation dose for different I.R'S. The removal of $\mathrm{Cr}$ (VI) increases mainly due to the enhanced total surface area of the adsorbent. And the adsorption of $\mathrm{Cr}(\mathrm{VI})$ is $\mathrm{pH}$ dependent. The removal efficiency of adsorbent increases with decrease in the $\mathrm{pH}$ value. 


\section{REFERENCES}

[1] APHA, "Standard Methods for the Examination of Water and Wastewater", $19^{\text {th }}$ edition (APHA, AWWA, and WFF Washington DC) (1995) pp 3.58-3.60.

[2] K.Swarna Lata, "Adsorption Studies of $\mathrm{Cr}$ (VI) on Activated Carbon Derived from Royal Poinciana (Gulmohar) Shell". M.Tech. Env. Engg. Dissertation Work, P.D.A.C.E.G, (2005-2006).

[3] WHO, (1963), Guidelines for drinking-water quality, World Health Organization, Geneva 